\title{
Bahçeli Bir Konut Örneğinde Yağmur Suyu Hasadı
}

\author{
Melike Yalıı Kılıç* Merve Nur Abuş \\ Bursa Uludağ Üniversitesi, Mühendislik Fakültesi, Çevre Mühendisliği Bölümü, Bursa
}

Geliş tarihi (Received): 24.05.2018～Kabul tarihi (Accepted): 28.06.2018

\begin{abstract}
Anahtar kelimeler:
Bursa, maliyet, su tüketimi, yağmur suyu hasadı

\section{*Sorumlu yazar}

myalili@uludag.edu.tr

Özet. Bu çalışmada yağmur suyu hasadıyla ilgili bilgiler verilmiş, örnek bir konutun çatısından toplanan yağmur sularının konut dışı su ihtiyacının karşılanmasındaki kullanım potansiyeli incelenmiştir. Bu amaçla konutun çatı alanı ve aylık yağı̧s verileri kullanılarak konutun çatısından toplanan yağmur suyu miktarı hesaplanmıştır. Ayrıca konut dışındaki yeşil alanların sulanmasında, süs havuzunun doldurulmasında, araç yıkamada ve kümes hayvanlarının su ihtiyacının karşılanmasında gereken su miktarı ve yağmur suyu ihtiyacı hesaplanarak, toplanan yağmur suyunun bu intiyacın ne kadarını karşılayacağının belirlenmesi için maliyet hesabı yapılmıştır. Illave olarak, yağmur suyu toplama sisteminin ve yıllık tasarruf edilen şebeke suyunun maliyetlerinin karşılaştıııması neticesinde uygulanan sistemin amortisman süresi de bulunmuştur.
\end{abstract}

\section{Rain Water Harvesting in a Garden House Sample}

\section{Keywords:}

Bursa, cost, water consumption, rain water harvesting

\begin{abstract}
In this study, some information was given about rain water harvesting and its potential to water supply was analyzed by sample taken from the roof of a model residence. Within this purpose, the amount of harvested rain water was calculated by using roof surface and monthly precipitation data. Furthermore, in order to determine how much water to be supplied, a cost analysis was made by calculating the amount of water to be used for irrigating the garden, filling in the pond, washing the car, and watering the barnyard fowl. Additionally, period of redemption was determined by comparison between the cost of rain water harvesting system and the cost of city water disposal per annum.
\end{abstract}




\section{GiRiş}

Su, nüfus artışı, iklim şartlarındaki değişim, çevre kirliliği, kontrolsüz su tüketimi gibi nedenlerle çevrimini tamamlayamadan tükenmektedir. Dünyadaki toplam su miktarı 1.4 milyar $\mathrm{km}^{3}$ tür. Bu suların \% 97.5'i okyanuslarda ve denizlerde tuzlu su olarak, \% 2.5'i ise nehir ve göllerde tatlı su olarak bulunmaktadır. Tatlı su kaynaklarının \% 90'ının kutuplarda ve yeraltında bulunması nedeniyle, insanların kullanabileceği su miktarının oldukça sınırlı olduğu görülmektedir (Yalııı Kılıç et al., 2008).

Su varlığına göre ülkeler sınıflandırıldığında yılda kişi başına düşen ortalama kullanılabilir su miktarı $1000 \mathrm{~m}^{3}$ 'ten az olan ülkeler su fakiri ülke, 1.000-3.000 $\mathrm{m}^{3}$ olan ülkeler su sıkıntısı çeken ülke, $3.000-10.000 \mathrm{~m}^{3}$ olan ülkeler suyun yeterli olduğu ülke, $10.000 \mathrm{~m}^{3}$ 'ten fazla olan ülkeler ise su zengini ülke olarak kabul edilmektedir (Alparslan et al., 2008; Şahin ve Manioğlu 2011). Kişi başına düşen kullanılabilir su miktarı 1.500$1.600 \mathrm{~m}^{3} \mathrm{yıl}^{-1}$ olan Türkiye, su sıkıntısı çeken ülke konumundadır. Gelecek 20 yıl içinde Türkiye nüfusunun 87.000.000'a çıkacağı, kişi başı su miktarının $1042 \mathrm{~m}^{3} \mathrm{yıl}^{-1}$ a düşeceği ve su fakiri ülkeler arasına katılacağımız öngörülmektedir (Eren et al., 2016; Yağmur suyu 2017).

Doğal kaynak olan suyun insanlar tarafından bilinçli ve israf edilmeden kullanılması hayli önemlidir. Tatlı su kaynaklarının sınırlı ve temiz su elde etme tekniklerinin maliyetli olması, insanları farklı arayışlara yöneltmiştir. Nüfusla birlikte artan su talebine karşın temiz su kaynaklarını yenileyerek miktarını arttırmak teknik ve ekonomik açıdan mümkün değildir. Bu durumda doğal kaynakların sürdürülebilir yönetimi için alternatif su kaynakları arayışına gidilmesi, son yıllarda pek çok ülkede uygulanan ve üzerinde önemle durulan bir konudur (Asano and Levine 1996; Sturm et al., 2009; Zhang et al., 2010; Alternatif Su Kaynakları 2018).

Yağmur sularının yalnızca \%30'u yeraltı sularına katılmakta, geri kalan \%70'lik kısmından faydalanılamamaktadır. Başta konut çatıları olmak üzere, yollar, kaldırımlar ve otopark gibi açık alanlardan borularla toplanan yağmur suları filtrelendikten sonra depoya alınmakta ve depolanan bu su bahçe sulama, araç yıkama, tuvalet rezervuarı, temizlik işleri vb. intiyaçlar için kullanılabilmektedir (Eren et al., 2016; Yağmur suyu 2017). Yağmur sularının bu şekilde toplanıp, depolanması ve farklı amaçlarla kullanılabilmesi neticesinde, hem su kaynakları korunmakta hem de ekonomik kazanç sağlanmaktadır.

Bu çalışmada alternatif bir su kaynağı olan yağmur suyunun önemi vurgulanmış ve yağmur suyu hasadı hakkında bilgiler verilmiştir. Illave olarak, bahçeli bir konutun çatısından toplanacak yağmur sularının aynı konutun yeşil alanlarının sulanmasında, süs havuzunun doldurulmasında, araç yıkanmasında ve kümes hayvanlarının su ihtiyacının karşılanmasındaki kullanım potansiyeli araştııılmıştır. Ayrıca, bu örnek konuta uygulanan yağmur suyu toplama sisteminin maliyeti ile yıllık tasarruf edilen şebeke suyu maliyeti karşılaştırılarak sistemin amortisman süresi hesaplanmıştır.

\section{YAĞMUR SUYU HASADI}

Yağmur suyu hasadı, yağmur sularının ve yüzeysel akışa geçen suların toplanıp biriktirilmesi ve bitkiselhayvansal üretim ile evsel tüketim için gerekli olan suyun sağlanmasıdır (Oweis et al., 2001; Kantaroğlu 2009). Yağmur suyu hasadı, Roma dönemindeki çatılardan yağmur suyu toplama sistemlerine kadar uzanmaktadır. Illk hasat örneği, Mısır'da bulunan 200 tondan 2000 tona kadar farklı boyutlardaki depolama tanklarıdır. Bu tankların bir kısmı günümüzde hala kullanılmaktadır. İstanbul'da artan nüfusun intiyaçlarını karşılamak için çeşitli suyolları ile beslenen geleneksel sarnıçlara ait pek çok örnek bulunmaktadır. Sarnıçların en bilinenleri 336 sütunlu İmparator Sarnıcı (Yerebatan Sarayı), 224 sütunlu Pileksenus Sarnıcı (Binbirdirek) ve Acımusluk Sarnıcı'dır. Ayrıca eski dönemlerde su kaynaklarının mevcut nüfusa yetersiz gelmesi nedeniyle özellikle tarihi yarımadada konutların ya da sarayların bodrum katları sarnıç olarak kullanılmıştır (Tema 2017).

Su hasadı teknikleri arasında bulunan çatı yüzeyinden su hasadı yönteminde çatı yüzeyine düşen yağış toplanmakta, yağmur olukları yardımıyla toprak yüzeyindeki bir tanka ya da yer altındaki bir depoya aktarılmaktadır (Şekil 1) (Pamuk Mengü ve Akkuzu 2008).

Evlerin çatılarından toplanan yağmur suları arıtılarak içme suyu seviyesine getirilebildiği gibi bina içerisinde çamaşır makineleri ve tuvalet rezervuarlarında ya da bina dışında bahçe sulama, araç yıkama ve süs havuzunu doldurmakta da kullanılabilmektedir (Şahin ve Manioğlu 2011). Yağmur sularının içme suyu amaçlı kullanılma durumunda suyun filtrasyonu, klorlanması ve dezenfekte edilmesi ya da kaynatılması gerekmektedir (Kantaroğlu 2009).

Yağmur suyunun toplanarak binalarda kullanımının yaygınlaştırııması çeşitli teşvik ve yasalarla desteklenmektedir. Günümüzde Hindistan'ın birçok şehrinde $100 \mathrm{~m}^{2 \prime}$ den büyük çatı alanına sahip tüm yeni binalarda ve $1000 \mathrm{~m}^{2 \prime}$ den büyük inşaat alanına sahip yeni binalarda, altyapısı bulunan şehirsel alanlarda, yağmur suyu kullanılması zorunlu hale getirilmiştir (Tema 2017). Fiji adalarında okulların ve devlet 

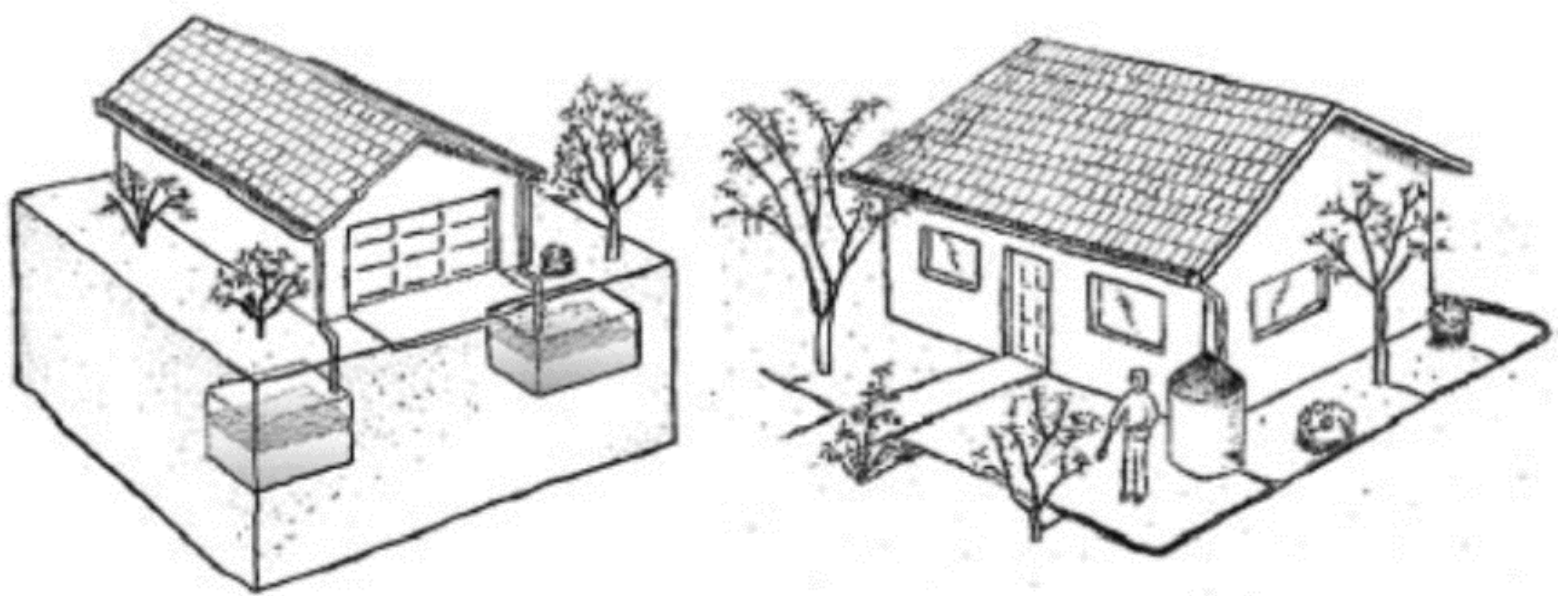

Şekil 1. Çatı yüzeyinden toplanan suyun depolama ortamı (Kantaroğlu 2009).

Figure 1. The storage area of the water collected from the roof surface.

kurumlarına ait binaların çatılarından, havaalanı vb. geniş yüzeye sahip yerlerden toplanan yağmur suları kullanılmaktadır. Tayland'da seksenli yıllardan bu yana çok sayıda beton sarnıç yapılmış olup, burada toplanan sular içme ve kullanma amaçlı değerlendirilmektedir. Amerika Birleşik Devletleri'nde ise yaklaşık 250.000 ev yağmur suyu toplama sistemine sahiptir. Karayipler'deki bazı adalarda yeni yapılara yağmur suyu toplama sistemi dahil edilmektedir (Alparslan et al., 2008; Incebel 2012). Japonya'da $30.000 \mathrm{~m}^{2}$ den büyük binalarda gri su arıtma sistemlerinin veya yağmur suyu toplama sistemlerinin kullanılması, Japonya Bayındırlık Bakanlığı tarafından yasa ile zorunlu hale getirilmiştir. Almanya'da yağmur suyu toplama sistemleri konusunda DIN (1989) standardına göre yağmur suyuna ilişkin planlama, tesisat, uygulama ile bakım, yağmur suyu filtreleme, yağmur suyu rezervuarları ve ek bileşenleri konuları ele alınmaktadır. Su fiyatlarının yüksek olması nedeniyle konutlarda ve çalışma alanlarında 1.5 milyonun üzerinde yağmur suyu toplama sistemi kurulmuştur. Sistemin kurulduğu bölgeye göre teşvik için 1200 Euro'ya kadar indirim yapılmaktadır. İngiltere'de yağmur suyu kullanımı konusunda BS 8515 (2009) yağmur suyu toplama sistemleri uygulama standardı çıkarılmıştır. Bu standart İngiltere'de yağmur suyunun kullanım suyuna eklenmesine ilişkin tasarımı, tesisatı ve bakımı hakkında bilgi vermektedir. Teşvik için sistemin uygulandığı ilk yıl \%100 vergi indirimi sağlanmaktadır (Şahin ve Manioğlu 2011). Ülkemizde ise yağmur suyu kullanımına ilişkin Yağmursuyu Toplama, Depolama ve Deşarj Sistemleri Hakkındaki Yönetmelik 30105 sayı ve 23.06.2017 tarih ile Çevre Şehircilik Bakanlığı tarafından Resmi Gazete'de yürürlüğe konulmuştur. Yağmursuyu hasat sistemlerinin çeşitlerine ait bilgilere Yönetmelik EK-1 de yer verilmiştir. Bu bölümde kullanma suyu temini amacıyla uygulanan yağmursuyu hasat sistemlerinin tasarımı, kurulumu, test edilmesi ve bakımı ile ilgili BS 8515 (2009) standardında yer alan hususlarda öneriler sunulmaktadır. BS 8515 (2009) standardı, içme suyu kalite standartlarını sağlaması beklenmeyen yıkama suyu, tuvalet suyu ve bahçe sulama suyu gibi evsel kullanma sularının (evsel, ticari, endüstriyel ve umuma mahsus yerlerdeki su intiyaçları) yağmur suyundan temin edilmesi ile ilgili hususları içermektedir. Söz konusu standart; içme, gıda hazırlama ile pişirme, bulaşık yıkama ve kişisel hijyenle ilgili su ihtiyaçlarının karşılanmasına dair hükümler içermemektedir. Yağmur suyunun yangın suyu veya ticari sulama suyu olarak kullanılmasıyla ilgili özel hükümler bulunmasa da bu alanlar standart kapsamı dışında bırakılmamıştır (Resmi Gazete 2017).

Yağmur suyunun toplanarak alternatif su intiyaçlarının giderilmesinde kullanılması hem su tasarrufu hemde su kaynaklarının korunması ve sürdürülebilirliği açısından büyük önem arz etmektedir. Ülkemizde bina çatılarından yağmur suyu hasadı kullanım teknolojilerine ilişkin çeşitli örnekler mevcuttur. Siemens Gebze Organize Sanayi Bölgesi'nde "Yeşil Bina Konsepti"nde su korunumuna ilişsin pek çok teknoloji geliştirilmiştir. Çatıdan toplanan yağmur suyunun yangın sulama tertibatında ve yumuşatılarak tüm alan içerisinde kullanım suyu olarak değerlendirilmesi, bina dışında ise peyzaj sulamasında kullanılması söz konusudur. Diyarbakır Güneş Evi'nde çatılardan toplanarak su deposuna gelen yağmur suyu ile evsel atıksu arıtımından elde edilen su, karbon filtreden geçirilerek bahçe sulamasında ve tuvalet rezervuarlarda kullanılmaktadır. Borusan Oto İstinye Tesisleri'nde çatılardan toplanan yağmur suları, ayrı depolarda 
toplanıp arıtılarak tuvalet rezervuarı, araç yıkama ile bahçe sulamada ve yangın deposunda kullanılmaktadır (Şahin ve Manioğlu 2011). Yeşil Bina Konsepti'yle tasarlanan Bursagaz'ın genel müdürlük binasının terasındaki yağmur suları ve binanın çevresindeki drenaj suları biriktirilip filtrelerden geçirilerek $20 \mathrm{~m}^{3}$ yağmur suyu depolanmakta ve depolanan bu su yeşil alanların sulanması ile tuvalet rezervuarlarında kullanılmaktadır (Bursagaz 2017). Bursa Hilton Otel, enerji verimliliğini arttıran ve çevreye duyarlı otellerde yer alan Yeşil Yıldız Konsepti'ne sahip örnek bir oteldir. Bu konsept, yağmur sularının veya arıtılmış atık suların bahçe sulaması ve/veya tuvalet rezervuarlarında kullanılmasını da kapsamaktadır (Hilton 2015).

\section{BULGULAR}

Bu çalışmada örnek alınan bahçeli bir konutun çatısından toplanacak yağmur suyu miktarının hesaplanması ve bu suyun konut dışı aktiviteler arasında yer alan bahçe sulama, kümes hayvanlarının günlük su ihtiyacı, süs havuzunun doldurulması, araba yıkama gibi ihtiyaçlarda kullanılabilirliğinin belirlenmesi amaçlanmıştır. Ayrıca konuta uygulanan yağmur suyu toplama sisteminin maliyeti ve amortisman süresi de hesaplanmıştır.

\section{Yağmur Suyu Verimi Hesabı}

Çatı yüzeyinden ne kadar yağmur suyunun toplanacağına ilişkin hesaplamalar aşağıda özetlenmiştir (Tema 2017).

Yağmur suyu verimi = Yağmur toplama alanı * yağış miktarı * çatı katsayısı * filtre etkinlik katsayısı.

Yağmur toplama alanı: Toplam çatı alanıdır.

Yağış miktarı: Meteoroloji Genel Müdürlüğü tarafından belirlenen toplam yıllık yağış miktarıdır.

Çatı katsayısı: Alman standartları tarafından DIN (1989)'da 0.8 olarak belirtilen katsayıdır. Çatı katsayısı, çatıya düşen bütün yağmurun geri dönüştürülemeyeceğini ifade etmektedir.

Filtre etkinlik katsayısı: Alman standartları tarafından DIN (1989)'da 0.9 olarak belirtilen katsayıdır. Filtre etkinlik katsayısı, çatıdan elde edilen yağmur suyunun görünen katı maddelerden ayrıştırılması için geçirilen ilk filtrenin verimlilik katsayısıdır. Suyun bir miktarının buradan geçemeyeceği hesaplanarak verilen bir katsayıdır.

Bu çalışmada örnek olarak alınan konutun çatı yüzey alanı 200 m²'dir. Bursa ilinde 1926 ile 2016 yılları arasında metrekareye düşen ortalama akış miktarı
707.5 mm (707.5 L m²) olarak ölçülmüştür (Çizelge 1) (Resmi İstatistikler 2017).

Bu veriler doğrultusunda çatının kapladığı alana düşen yağış miktarı;

Yağmur suyu verimi = Yağmur toplama alanı * yağış miktarı * 0.8 * 0.9

Yağmur suyu verimi $=200 \mathrm{~m}^{2} * 707.5 \mathrm{~L} \mathrm{~m}^{-2 *} 0.8$ * 0.9 $=101.880 \mathrm{~L}=101.88 \mathrm{~m}^{3} \mathrm{yll}^{-1} \approx 102 \mathrm{~m}^{3} \mathrm{yll}^{-1}$

\section{Yıllk Toplam Su ihtiyacı}

Konutlarda, kullanma suyu miktarı evsel kullanım miktarının \%78'ini oluşturmaktadır. Bu oranın \%59'u konut dışında bahçe sulamasında, \%19'luk kısmı ise konut içerisinde kullanılmaktadır. Konut içerisinde tesisat maliyeti, yağmur suyunun konut dışında kullanılmasını daha uygun duruma getirmektedir. Bu nedenle yağmur suyunun basit bir şekilde toplanarak bahçe sulamasında kullanılması oldukça yaygın bir uygulamadır (Şahin ve Manioğlu 2011).

Bu çalışmada örnek alınan konutun $400 \mathrm{~m}^{2}$ alana sahip bir bahçesi bulunmaktadır. Bahçe içerisinde altı adet kümes hayvanı yetiştirilmekte ve $3.5 \mathrm{~m}^{3 \prime}$ lük bir süs havuzu yer almaktadır. Konut sahibine ait bir araç, konut dışı aktiviteler için su kullanımı hesabına dahil edilmiştir.

\section{Bahçe sulaması için gereken su miktarı hesabl;}

Yeşil alanların su ihtiyacının hesaplanmasında her bir sulama için su miktarı $5 \mathrm{~L} \mathrm{~m}^{-2}$ olarak kabul edilmiştir (Eren et al., 2016).

$400 \mathrm{~m}^{2}$ lik bir bahçe sulaması için;

$$
400 \mathrm{~m}^{2} * 5 \mathrm{~L} \mathrm{~m}^{-2}=2000 \mathrm{~L}=2 \mathrm{~m}^{3} \text { gün }^{-1}
$$

Her gün sulama yapılırsa; $2 \mathrm{~m}^{3}$ gün$^{-1}$ * 365 gün $=730$ $\mathrm{m}^{3} \mathrm{yll}^{-1}$

Haftada 2 kez sulama yapılırsa; $2 \mathrm{~m}^{3}$ gün $^{-1}$ * 365/(7/2) gün $=208.6 \mathrm{~m}^{3} \mathrm{yll}^{-1}$

Haftada 1 kez sulama yapııırsa; $2 \mathrm{~m}^{3}$ gün$^{-1}$ * $365 / 7$ gün $=104.3 \mathrm{~m}^{3} \mathrm{yll}^{-1}$

Bahçe sulama suyu ihtiyaçları, sulamanın her gün, haftada iki kez ve haftada bir kez yapıldığı durumlar için ayrı ayrı hesaplanmış ve Çizelge 2'de verilmiştir. Buna göre sulamanın her gün yapılması durumunda çatı alanlarından toplanan su miktarı; toplam bahçe sulama suyu ihtiyacının \%14'ünü, sulamanın haftada iki kez yapılması durumunda toplam bahçe sulama suyu ihtiyacının \%49'unu ve sulamanın haftada bir kez yapılması durumunda toplam bahçe sulama suyu ihtiyacının \%98'ini karşılayacağı tespit edilmiştir. 
Çizelge 1. Bursa'da yıllara bağlı (1926-2016) olarak gerçekleşen ortalama akış değerleri (mm). Table 1. Average flow values in Bursa due to the years $(\mathrm{mm})$.

\begin{tabular}{|c|c|c|c|c|c|c|c|c|c|c|c|c|c|}
\hline Aylar & 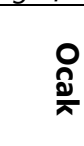 & 兄 & $\begin{array}{l}3 \\
\frac{2}{7}\end{array}$ & $\begin{array}{l}\text { Z. } \\
\text {. } \\
\text { J }\end{array}$ & $\underset{n}{3}$ & 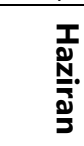 & $\begin{array}{l}-1 \\
\frac{1}{3} \\
3 \\
\frac{3}{N}\end{array}$ & 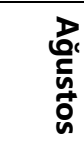 & $\underset{\text { ! }}{\text { m }}$ & 吕 & $\begin{array}{l}\text { त्ञ } \\
\underline{\underline{n}}\end{array}$ & $\frac{\frac{D}{2}}{\frac{D}{\pi}}$ & Toplam \\
\hline $\begin{array}{c}\text { Yağış } \\
\text { miktarı } \\
\text { (mm) }\end{array}$ & 89.1 & 76.7 & 70.1 & 63.0 & 49.2 & 33.3 & 21.6 & 16.6 & 42.0 & 66.8 & 78.4 & 100.7 & 707.5 \\
\hline
\end{tabular}

Çizelge 2. Bahçe sulama suyu ihtiyaçları.

Table 2. The needs of garden irrigation water.

\begin{tabular}{|c|c|c|c|c|c|c|c|}
\hline \multirow{2}{*}{$\begin{array}{c}\text { Çatı } \\
\text { yağmur } \\
\text { suyu } \\
\text { miktarı } \\
(\text { Yıllık, m³) }\end{array}$} & \multirow{2}{*}{$\begin{array}{l}\text { Yeşil alan } \\
\text { su } \\
\text { ihtiyacı } \\
\left(\mathbf{m}^{3}\right)\end{array}$} & \multicolumn{2}{|c|}{ Her gün sulama } & \multicolumn{2}{|c|}{ Haftada iki kez sulama } & \multicolumn{2}{|c|}{ Haftada bir kez sulama } \\
\hline & & $\begin{array}{c}\text { Su } \\
\text { ihtiyacı } \\
\left(\mathrm{m}^{3}\right)\end{array}$ & $\begin{array}{c}\text { Karşılanan } \\
\text { su ihtiyacı } \\
\text { yüzdesi } \\
(\%)\end{array}$ & $\begin{array}{c}\text { Su } \\
\text { ihtiyacı } \\
\left(\mathrm{m}^{3}\right)\end{array}$ & $\begin{array}{c}\text { Karşılanan su } \\
\text { ihtiyacı } \\
\text { yüzdesi } \\
\text { (\%) }\end{array}$ & $\begin{array}{c}\text { Su } \\
\text { ihtiyacı } \\
\left(\mathbf{m}^{3}\right)\end{array}$ & $\begin{array}{c}\text { Karşılanan su } \\
\text { ihtiyacı } \\
\text { yüzdesi } \\
\text { (\%) }\end{array}$ \\
\hline 102 & 2 & 730 & 14 & 208.6 & 49 & 104.3 & 98 \\
\hline
\end{tabular}

\section{Kümes hayvanlarının su ihtiyacl;}

Kümes hayvanlarının günlük su ihtiyacının hesaplanmasında, her bir kümes hayvanı için ihtiyaç duyulan su miktarı 0.25 L/gün olarak kabul edilmiştir (iller Bankası 2013).

Örnek konutta yetiştirilen altı tavuk için yıllık su ihtiyacl;

$$
\begin{aligned}
& 0.25 * 6=1.5 \mathrm{~L}=0.0015 \mathrm{~m}^{3} \mathrm{gün}^{-1} \\
& 0.0015 * 365=0.55 \mathrm{~m}^{3} \mathrm{yll}^{-1}
\end{aligned}
$$

Süs havuzunun doldurulması için gereken su miktarl;

Örnek konutta bulunan $3.5 \mathrm{~m}^{3}$ 'lük süs havuzunun doldurulması için gereken su miktarının hesaplanmasında, yılda iki kez doldurulup boşaltılacağı düşünülerek ihtiyaç duyulan su miktarı;

$$
3.5 * 2=7 \mathrm{~m}^{3} \mathrm{yll}^{-1}
$$

Araba yıkaması için gereken su miktarl;

Araba yıkamak için gereken su miktarl; bir seferde yaklaşık 50 litre su harcanacağı kabul edilmektedir (Araç yıkama 2013). Ayda bir kez araba yıkanacağı varsayılarak ihtiyaç duyulan yıllık su miktarı;

$$
50 * 12=600 \mathrm{~L}=0.6 \mathrm{~m}^{3} \mathrm{yll}^{-1}
$$

Yıllık Toplam Su Ihtiyacl;

Haftada iki kez bahçe sulanmasının yeterli olacağı düşünülerek,

Yıllık toplam su ihtiyacı = Bahçe sulaması için gereken su ihtiyacı + kümes hayv.su ihtiyacı + süs hav.su ihtiyacı + araba yıkama için gereken su ihtiyacı
$208.6 \mathrm{~m}^{3} \mathrm{yll}^{-1}+0.55 \mathrm{~m}^{3} \mathrm{yll}^{-1}+7 \mathrm{~m}^{3} \mathrm{yll}^{-1}+0.6 \mathrm{~m}^{3} \mathrm{yll}^{-1}$ $=216.75 \mathrm{~m}^{3} \mathrm{yıl}^{-1}$ dır.

Çatıdan toplanan yağmur suyu miktarı/kullanılan su miktarı $=102 / 216.75=0.47 \mathrm{yll} \approx 172$ gün

Depoda toplanan suyun 172 gün boyunca konut dışı aktivitelerde kullanılabileceği belirlenmiştir.

\section{Depo hacmi hesabi;}

Sistemin depo hacmi hesabı, maksimum yağışın olduğu Aralık ayı düşünülerek yapılmıştır (Çizelge 1). Aralık ayı: $100.7 \mathrm{~mm}$

Depo hacmi $=$ yağış miktarı ${ }^{*}$ çatı metrekaresi ${ }^{\star} 0.8 * 0.9$ $100.7 \mathrm{~L} \mathrm{~m}^{-2}$ * $200 \mathrm{~m}^{2}$ * 0.8 * $0.9=14,501 \mathrm{~L}=14.5$ $\mathrm{m}^{3}$ lük depo hacmi gerekmektedir.

\section{Yağmur Suyu Toplama Sisteminin Amortisman Süresi}

Yağmur Suyu Toplama Sisteminin Maliyeti:

Yağmur suyu toplama sistemi için gerekli ekipman, yağmur suyu filtresi, dalgıç pompa ve yağmur suyu deposudur. Ekipmanın özelliği ve maliyeti Çizelge 3'te verilmektedir.

Buradan yağmur suyu toplama sistem maliyeti 3.463 TL olarak hesaplanmaktadır.

\section{Yıllık tasarruf edilen tutar:}

Yıllık toplam $216.75 \mathrm{~m}^{3}$ su tüketimi olan örnek konutun $102 \mathrm{~m}^{3}$ lük su kullanımı yağmur suyundan karşılanabilmektedir. 
Çizelge 3. Yağmur suyu toplama sistemi ekipmanının maliyeti.

Table 3. The cost of rain water collection system equipment.

\begin{tabular}{cccc}
\hline Ekipman & Birimleri & Özellikleri & Maliyet (TL) \\
\hline Yağmur suyu deposu & Hacim- $15 \mathrm{~m}^{3}$ & Polietilen & 3000 \\
\hline Filtre & Hız-4000 $\mathrm{m}^{3} \mathrm{~h}^{-1}$ & Paslanmaz çelik/Kendini temizleme & 196 \\
tipi & Paslanmaz temiz su dalgıç pompa & 267 \\
\hline
\end{tabular}

Tasarruf edilen yıllık su miktarı $102 \mathrm{~m}^{3}$ ve Bursa Su ve Kanalizasyon İdaresi'nin (BUSKI) su satış fiyatı (şebeke suyu ücreti) atıksu bedeli dahil 3.28 TL m³ (Abone Rehberi 2017);

Yıllık tasarruf edilen tutar $=102 \mathrm{~m}^{3} * 3.28 \mathrm{TL} \mathrm{m}^{-3}=335 \mathrm{TL}$

Toplam tüketimin \%47'si yağmur suyundan sağlanabilmekte ve yıllık olarak 335 TL tasarruf edilebilmektedir.

\section{Sistemin amortisman süresi:}

Toplam sistem maliyeti / yıllık tasarruf edilen maliyet

$$
=3.463 \mathrm{TL} / 335 \mathrm{TL}=10.3 \mathrm{yll}
$$

\section{SONUÇ VE TARTIŞMA}

İçme ve kullanma amaçlı tüketilen suyun \%70'i tuvaletler, bahçe sulama, araç ve çamaşır yıkama gibi işler için kullanılmaktadır. Yağmur sularının yalnızca \%30'u yeraltı sularına katılmakta ve geri kalan \%70'lik kısmı doğrudan kanalizasyona karışmaktadır. Suyun canlılar için önemi göz önünde bulundurulduğunda, yağmur sularının değerlendirilmesinin ne derece önemli olduğu ortaya çıkmaktadır (Eren et al., 2016).

Bu çalışmada yağmur suyu hasadıyla ilgili bilgiler verilmiş, örnek bir konutun 200 m² $^{2}$ yüzey alanına sahip çatısından toplanacak yağmur suyunun konut dışı su ihtiyacının karşılanmasındaki kullanım potansiyeli incelenmiştir. Bu amaçla Bursa ili aylık yağış verileri kullanılarak konutun çatısından toplanacak yağmur suyu miktarı hesaplanmıştır. Toplanabilecek yağmur suyu ile karşılanan su ihtiyacı yüzdeleri sulamanın her gün, haftada iki kez ve haftada bir kez yapılması durumları için ayrı ayrı hesaplanmış; kümes hayvanlarının yıllık su ihtiyacı, süs havuzunun yılda iki kez doldurulması ve ayda bir kez araba yıkama aktiviteleri için su ihtiyacı her üç durum için de sabit tutulmuştur (Çizelge 4 ).

Örnek konutun çatısından toplanacak yağmur suyunun 172 gün boyunca bahçe sulamasında, süs havuzunun doldurulmasında, araç yıkama ve kümes hayvanlarının su ihtiyacının karşılanmasında kullanılabileceği belirlenmiştir. Konuta yapılacak yağmur suyu toplama sisteminin toplam maliyeti 3.463 TL olarak hesaplanmıştır. Konutun toplam su tüketiminin \%47'si yağmur suyundan elde edilmekte ve yıllık olarak $335 \mathrm{TL}$ tasarruf sağlanabilmektedir. Örnek konuta uygulanan yağmur suyu toplama sisteminin maliyeti ve yıllık tasarruf edilen şebeke suyu maliyeti karşılaştırıldığında, sistemin amortisman süresi 10.3 yıl olarak bulunmuştur.

Yapılan tüm bu hesaplamalardan yola çıkılarak, örnek konuta uygulanan yağmur suyu toplama sisteminin avantajlı bir sistem olduğu sonucuna varılmaktadır. Su sıkıntısının çekildiği ve su temininin büyük maliyetlere yol açtığı günümüzde, yağmur suyu hasadı gibi hem ucuz hem de pratik sistemler yaygınlaştırılmalıdır. Bu sistemlerin yaygınlaştırılması ile ekolojik dengenin korunacağı, sürdürülebilir kalkınmanın sağlanacağı ve su kaynaklarının daha verimli kullanılacağı düşünülmektedir.

Çizelge 4. Karşılanan su ihtiyacı yüzdeleri.

Table 4. The percentage of water needed.

\begin{tabular}{|c|c|c|c|c|c|c|}
\hline \multirow{2}{*}{$\begin{array}{c}\text { Çatı } \\
\text { yağmur } \\
\text { suyu } \\
\text { miktarı } \\
\left(\mathrm{m}^{3} \mathrm{yll}^{-1}\right)\end{array}$} & \multicolumn{2}{|c|}{$\begin{array}{c}\text { Bahçe sulama } \\
\text { (Her gün) }\end{array}$} & \multicolumn{2}{|c|}{$\begin{array}{c}\text { Bahçe sulama } \\
\text { (Haftada iki kez) }\end{array}$} & \multicolumn{2}{|c|}{$\begin{array}{c}\text { Bahçe sulama } \\
\text { (Haftada bir kez) }\end{array}$} \\
\hline & $\begin{array}{c}\text { Su } \\
\text { ihtiyacı } \\
\left(\mathrm{m}^{3} \mathrm{yll}^{-1}\right)\end{array}$ & $\begin{array}{c}\text { Karşılanan su } \\
\text { ihtiyacı } \\
\text { yüzdesi } \\
(\%) \\
\end{array}$ & $\begin{array}{c}\text { Su } \\
\text { ihtiyacı } \\
\left(\mathrm{m}^{3} \mathrm{yll}^{-1}\right)\end{array}$ & $\begin{array}{c}\text { Karşılanan su } \\
\text { ihtiyacı } \\
\text { yüzdesi } \\
(\%) \\
\end{array}$ & $\begin{array}{c}\text { Su } \\
\text { ihtiyacı } \\
\left(\mathrm{m}^{3} \mathrm{yll}^{-1}\right)\end{array}$ & $\begin{array}{c}\text { Karşılanan su } \\
\text { ihtiyacı } \\
\text { yüzdesi } \\
(\%) \\
\end{array}$ \\
\hline 102 & 738.15 & 14 & 216.75 & 47 & 112.45 & 91 \\
\hline
\end{tabular}




\section{KAYNAKLAR}

Abone Rehberi 2017. http://www.buski.gov.tr/tr/ abonerehberi /kategori_17 [Erişim: 04 Aralık 2017].

Alparslan N., Tanık A ve Dölgen D., 2008. Türkiye'de Su Yönetimi Sorunlar ve Öneriler. Türk Sanayicileri ve İşadamları Derneği (TÜSIAD) Yayın No: T/2008-09/469.

Alternatif Su Kaynakları 2018. http://docplayer.biz.tr/ 192040-Alternatif-su-kaynaklari.html [Erişim: 12 Haziran 2018].

Araç yıkama 2013. Araç yıkamada harcadığımız su ile 5 yılda bir baraj kuruyor. http://www.ciftlikdergisi.com.tr/aracyikamada-harcadigimiz-su-ile-5-yilda-bir-barajkuruyor.html [Erişim: 06 Kasım 2017].

Asano T and Levine A.D., 1996. Wastewater reclamation, recycling and reuse: past, present, and future, Water Science and Technology, 33(10-11): 1-14.

BS 2009. Rainwater Harvesting Systems-Code of Practice. British Standard 8515: 2009, London.

Bursagaz 2017. Bursagaz'a yeşil bina sertifikası. http://www.milliyet.com.tr/bursagaz-a-yesil-binasertifikasi-bursa-yerelhaber-1991153/ [Erişim: 01 Aralık 2017].

DIN 1989. Regenwassernutzungsanlagen. Deutsches Institut Normung DIN: 1989, German.

Eren B., Aygün A., Likos S ve Damar A.I.., 2016. Yağmur Suyu Hasadı: Sakarya Üniversitesi Esentepe Kampüs Örneği. International Symposium on İnnovative Technologies in Engineering and Science (ISITES), 3-5 November, Antalya.

Hilton 2015. Hilton Bursa yeşil yıldız belgesi aldı. http://www.turizmgazetesi.com/news.aspx?id=76656 [Erişim: 01 Aralık 2017].

Iller Bankası 2013. https://www.ilbank.gov.tr/dosyalar/ icmesuyu/ICMESUYU_ETUT_FIZB_TEKN_SART.pdf [Erişim: 06 Kasım 2017].

İncebel C., 2012. Alternatif su kaynaklarının endüstriyel kullanıma kazandırılması için çatı yağmur suyu hasadı (Ostim örneği). Yüksek Lisans Tezi, Gazi Üniversitesi Fen Bilimleri Enstitüsü, Ankara.
Kantaroğlu Ö., 2009. Yağmur suyu hasadı plan ve hesaplama prensipleri. IX. Ulusal Tesisat Mühendisliği Kongresi, 6-9 Mayıs, İzmir.

Oweis T., Prinz Dand Hachum A., 2001. Water Harvesting: Indigenous Knowledge for The Future of The Drier Environments. International Center for Agricultural Research in the Dry Areas (ICARDA), Aleppo, Syria.

Pamuk Mengü G veAkkuzu E., 2008. Küresel su krizi ve su hasadı teknikleri. Adnan Menderes Üniversitesi Ziraat Fakültesi Dergisi, 5(2): 75-85.

Resmi Gazete 2017. T.C. Resmi Gazete, 30105, 23.06.2017. http://www.resmigazete.gov.tr/eskiler/2017/06/2017062 3-8.htm [Erişim: 20 Aralık 2017].

Resmi İstatistikler 2017. https://www.mgm.gov.tr/ veridegerlendirme/il-ve-ilceler-istatistik.aspx?m= BURSA [Erişim: 06 Kasım 2017].

Sturm M., Zimmermann M., Schutz K., Urban W and Hartung $H ., 2009$. Rainwater harvesting as an alternative Water resource in rural sites in central northern Namibia. Physics and Chemistry of the Earth, 34: 776-785.

Şahin N ve Manioğlu G., 2011. Binalarda yağmur suyunun kullanılması. Tesisat Mühendisliği, 125: 21-32.

Tema 2017. TEMA - Geleceğin suyu. http://sutema.org/ resources/Document/FileName/2015-12-01_22-11-14692\%20GeleceginSuyu.pdf [Erişim: 20 Aralık 2017].

Yağmur suyu 2017. Yağmur suyu filtreleme ve depolama sistemi. http://www.sfr.com.tr/yagmur-suyu-hasatis6.html [Erişim: 08 Kasım 2017].

Yalıı Kılıç M., Kestioğlu K ve Aydınalp C., 2008. Atıksuların Sulama Suyu Olarak Kullanım Olanaklarının Değerlendirilmesi. Su Tüketimi Arıtma Yeniden Kullanım Sempozyumu, 3-5 Eylül, Bursa.

Zhang Y., Grant A., Sharma A., Chen D and Chen L., 2010. Alternative water resources for rural residential development in Western Australia. Water Resource Management, 24: 25-36. 